\title{
Feasibility of transanal total mesorectal excision in cases with challenging patient and tumor characteristics
}

\author{
Dae Kyung Sohn*, Sung Chan Park*, Min Jung Kim, Hee Jin Chang, Kyung Su Han, Jae Hwan Oh \\ Center for Colorectal Cancer, Research Institute and Hospital, National Cancer Center, Goyang, Korea
}

\begin{abstract}
Purpose: To assess the feasibility of transanal total mesorectal excision in difficult cases including obese patients or patients with bulky tumors or threatened mesorectal fascias.

Methods: We performed laparoscopy-assisted transanal total mesorectal excision in patients with biopsy-proven rectal adenocarcinoma located 3-12 cm from the anal verge as part of a prospective, single arm, pilot trial. The primary endpoint was resection quality and circumferential resection margin involvement. Secondary endpoints included the number of harvested lymph nodes and 30-day postoperative complications.

Results: A total of 12 patients ( 9 men and 3 women) were enrolled: one obese patient, 7 with large tumors and 8 with threatened mesorectal fascias ( 4 patients had multiple indications). Tumors were located a median of $5.5 \mathrm{~cm}$ from the anal verge, and all patients received preoperative chemoradiotherapy. Median operating time was 191 minutes, and there were no intraoperative complications. One patient needed conversion to open surgery for ureterocystostomy after en bloc resection. Complete or near-complete excision and negative circumferential resection margins were achieved in all cases. The median number of harvested lymph nodes was 15.5. There was no postoperative mortality and 3 cases of postoperative morbidity 11 postoperative ileus, 1 wound problem near the stoma site, and 1 anastomotic dehiscence).

Conclusion: This pilot study showed that transanal total mesorectal excision is also feasible in difficult laparoscopic cases such as in obese patients or those with bulky tumors or tumors threatening the mesorectal fascia. Additional larger studies are needed.
\end{abstract}

[Ann Surg Treat Res 2019;96(3):123-130]

Key Words: Laparoscopy, Rectal neoplasms, Transanal endoscopic surgery

\section{INTRODUCTION}

The introduction of total mesorectal excision (TME) in the 1990s and laparoscopic surgery in the 2000s have led to significant improvements in patient care [1,2]. Several studies have shown that laparoscopic TME surgery provides rapid recovery and satisfactory short-term and long-term oncologic outcomes [3-5]. Thus, it has been accepted as the standard surgical procedure for rectal cancer and is widely used by experienced surgeons worldwide.

Nevertheless, the conversion rate during laparoscopic TME surgery has been reported to be as high as 5\%-30\% [6,7]. Since conversion can impair not only short-term outcomes but also long-term survival rates, additional solutions are needed. It is well known that the conversion rate increases in challenging patients such as the obese, men, and those with a narrow pelvis, bulky tumors, or surrounding organ invasion $[6,8$ 10]. Most of these reasons are attributed to the difficulty in ensuring sufficient surgical field in a narrow space and the smooth operation of the surgical instrument.

Since the first transanal TME procedure was performed in patients with rectal cancer by Sylla et al. [11] in 2010, several
Received July 25, 2018, Revised September 20, 2018,

Accepted October 16, 2018

Corresponding Author: Jae Hwan Oh

Center for Colorectal Cancer, National Cancer Center, 323 IIsan-ro, Ilsandong-gu, Goyang 10408, Korea

Tel: +82-31-920-1505, Fax: +82-31-920-1511

E-mail: jayoh@ncc.re.kr

ORCID code: https://orcid.org/0000-0002-5883-5815
*Dae Kyung Sohn and Sung Chan Park contributed equally to this work as co-first authors.

Copyright (C) 2019, the Korean Surgical Society

(c) Annals of Surgical Treatment and Research is an Open Access Journal. All articles are distributed under the terms of the Creative Commons Attribution NonCommercial License (http://creativecommons.org/licenses/by-nc/4.0/) which permits unrestricted non-commercial use, distribution, and reproduction in any medium, provided the original work is properly cited. 
researchers have suggested that it could be beneficial in patients with lower rectal cancer, especially those with narrow pelvis or bulky tumors $[10,12]$. This is because the scope can directly visualize the surgical site during the lower rectal dissection and that the use of straightened surgical instruments is relatively straightforward in transanal approaches. However, there are no clinical trials to support this suggestion.

This prospective study was conducted to assess the technical feasibility of transanal TME in these difficult laparoscopic cases including obese patients or patients with bulky tumors or tumors threatening the mesorectal fascia.

\section{METHODS}

This prospective study enrolled 12 patients with biopsyproven rectal adenocarcinoma who underwent transanal TME from April 2015 to February 2017 at the Center for Colorectal Cancer, National Cancer Center Korea. All investigations were conducted according to the principles in the Declaration of Helsinki. The Institutional Review Board of the National Cancer Center approved this study (NCC2015-0050), and the written informed consents were obtained from all participants. The study protocol was registered at clinicaltrial.gov (NCT02421432).

\section{Patient's enrollment and study design}

The inclusion criteria were patients' age between 20 and 80 years, histologically confirmed adenocarcinoma located 3 to 12 $\mathrm{cm}$ from the anal verge, and an Eastern Cooperative Oncology Group score no greater than 2. Preoperative evaluations included serum carcinoembryonic antigen levels, colonoscopy, rectal MRI, and CT of the chest and abdomen. Based on these preoperative evaluations, only patients with rectal cancers with no evidence of distant metastasis (M0) were enrolled. Finally, patients with any one of the followings were enrolled: (1) Patients with a body mass index (BMI) greater than $30 \mathrm{~kg} /$ $\mathrm{m}^{2}$, (2) a tumor larger than $7 \mathrm{~cm}$ in diameter, or (3) involvement of the mesorectal fascia or adjacent organs or a circumferential resection margin (CRM) measured less than $1 \mathrm{~mm}$ on rectal MRI. The exclusion criteria were: synchronous colon cancer or other malignancy, obstructing rectal cancer, pregnancy or breastfeeding, receiving any other study agents, and a history of prior colorectal cancer or inflammatory bowel disease. According to our institution's standard treatment protocol, patients with clinically staged T3/T4 or node-positive mid or low rectal cancer received 45-Gy pelvic radiation therapy in 25 fractions followed by a 5.4-Gy boost in 3 fractions. Preoperative chemotherapy (capecitabine) was started on the first day of pelvic radiotherapy. Surgical resection was performed 6 to 8 weeks after chemoradiotherapy (CRT) was completed.

\section{Operative techniques}

Two teams of colorectal surgeons performed transabdominal and transanal procedures simultaneously. Three surgeons performed the transanal offstage of transanal TME. All surgeons were experienced, having performed transanal TME procedures in animal and human cadaver models and at least 5 patients. The transabdominal and transanal procedures have been standardized using video review in our previous study on transanal TME [13-15].

\section{Transabdominal approach}

The transabdominal approach was performed either with a conventional multiport laparoscopic method or single incision laparoscopic surgery using a single-port trocar (Octoport; Dalim, Seoul, Korea). The transabdominal procedure was started using a medial approach to expose the inferior mesenteric vessels. After ligation of the inferior mesenteric vessels, full mobilization of the sigmoid and descending colon was performed. Additional downward dissection was continued to the level of the peritoneal reflection anteriorly and the level of the sacral promontory posteriorly.

In the single incision laparoscopic approach, if additional assistant ports were required during the procedure, one or more trocars were inserted at the surgeon's discretion. When the transanal dissection reached the peritoneal cavity, transabdominal laparoscopic instruments were used to assist the down-to-up dissection for more effective exposure and traction.

\section{Transanal approach}

Patients were placed in the lithotomy position, and a Lone Star Retractor (Lone Star Medical Products, Houston, TX, USA) was used for exposure. If the tumor was located within $3 \mathrm{~cm}$ of the anorectal ring, a full-thickness circumferential rectal incision was made followed by secure closure of the rectal stump with purse-string sutures. After closing the rectal stump, the surgical field was irrigated with povidone-iodine solution and normal saline to prevent infection and the implantation of cancer cells. For more proximal tumors, a transanal platform (Gelpoint path; Applied Medical, Rancho Santa Margarita, CA, USA; or transanal endoscopic operation proctoscope; Karl Storz, Tuttlingen, Germany) was first introduced into the anal canal. After marking by electric diathermy at least $1 \mathrm{~cm}$ distal to the lower edge of the tumor, tight purse-string sutures were placed to close the lumen. A pneumorectum or pneumoperirectum was created at a pressure of $8-10 \mathrm{mmHg}$ and a $\mathrm{CO}_{2}$ flow of $5-10$ $\mathrm{L} / \mathrm{min}$. A standard flexible $10-\mathrm{mm}$ camera and conventional laparoscopic instruments were used.

After full-thickness circumferential transection $1 \mathrm{~cm}$ distal to the purse-string suture, transanal dissection was initiated from the posterior side to identify the presacral avascular 
plane. Subsequently, an anterior dissection was performed in the rectovaginal or rectoprostatic plane by cutting the rectourethralis muscle. Further dissection was carefully extended to both lateral sides of the rectum, avoiding damage to the neurovascular bundles located at the anterolateral side of the rectal wall. Circumferential mobilization proceeded cephalad to the level of the peritoneum until the planes of dissection communicated with each other.

\section{Specimen extraction and anastomosis}

After full mobilization of the colon and rectum was completed, specimen extraction was performed through the abdominal incision site. Anastomosis was subsequently completed via hand-sewing or single stapling. Since the patients had received preoperative radiation therapy, a temporary diversion ileostomy was made at the incision site.

\section{Outcome measurements}

The primary endpoint was the quality of the TME and the CRM. Secondary endpoints included the number of harvested lymph nodes, operation time, and 30-day postoperative complications. An experienced pathologist evaluated surgical specimens and classified them using the $\mathrm{T}$ and $\mathrm{N}$ staging system. The pathologist also used a 3-point grading system proposed by Quirke et al. [16] for mesorectal grading according to the presence of defects or tears: complete, nearly complete, or incomplete. A positive CRM was defined as a margin of normal tissue $1 \mathrm{~mm}$ or less from the edge of the original tumor. Postoperative complications were classified according to the Clavien-Dindo classification of surgical complications [17]. Anastomotic dehiscence was defined as any defect in the integrity of the intestinal wall at the anastomosis site or a pelvic abscess around the anastomotic site, regardless of the presence of clinical symptoms. Urinary retention was defined as the inability to spontaneously void or as incomplete voiding requiring either self-catheterization or Foley catheter replacement after postoperative day 5. Postoperative ileus was defined as the absence of bowel function for 5 or more days or the need for reinsertion of a nasogastric tube after starting an oral diet without signs of mechanical obstruction. Patient and tumor characteristics, operative findings, and length of hospital stay were also recorded. Quantitative data were reported as medians and ranges.

\section{RESULTS}

A total of 12 patients, including 9 men and 3 women, were enrolled this study. The indications were: 1 case with BMI over $30 \mathrm{~kg} / \mathrm{m}^{2}, 7$ with a large tumor over $7 \mathrm{~cm}$ in diameter, and 8 with a threatened mesorectal fascia, including 4 cases with concurrent large tumors. Median patient age was 65.5 years (range, 45-80 years) and median BMI was $25.9 \mathrm{~kg} / \mathrm{m}^{2}$ (range, $16.9-30.3 \mathrm{~kg} / \mathrm{m}^{2}$ ). Tumors were located a median of $5.5 \mathrm{~cm}$ (range, $3.0-10.0 \mathrm{~cm}$ ) from the anal verge and median tumor size was $8.0 \mathrm{~cm}$ (range, 3-9 cm). All patients received preoperative CRT. The median interval between the last administration of CRT and operation was 56 days (range, 44-86 days). The clinical characteristics of the enrolled patients are summarized in Table 1.

\section{Operative outcome}

Median operating time was 191 minutes (range, 149-510 minutes). Median estimated blood loss was $100 \mathrm{~mL}$ (range, 50-300 mL) and no patient required transfusion. There were no intraoperative complications. There was 1 case of conversion to open surgery in a patient with a rectal tumor invading the right ureter. Laparoscopic uretero-ureterostomy was attempted after en bloc tumor resection, including a segment of the right ureter, but the length of the ureter was insufficient and conversion to open surgery and ureterocystostomy were performed.

A transabdominal approach with single-port laparoscopy was completed successfully in 3 patients without additional trocars and in 1 with an additional 5-mm port. In 8 patients, conventional multiport laparoscopy using 4 to 6 ports was performed. Splenic flexure mobilization was performed in 5 patients, in which conventional multiport laparoscopy was performed. For the transanal approach, the soft-type platform was used in 8 patients, and the rigid-type platform was used in 4 . The intersphincteric resection was performed in 6 patients with hand-sewn coloanal anastomosis and stapled anastomosis with a circular stapler was performed in the other 6. Transabdominal specimen extraction was performed in all patients. In 4 patients, the specimen was extracted through the single port trocar site, and in 8 patients operated upon using a conventional multiport trocar, the specimen was extracted through an additional incision. Diverting ileostomy was performed at the specimen extraction site. Operative outcomes in detail are shown in Table 1. The procedure time for each step and operative details are described in Table 2.

\section{Pathologic outcome}

Complete (10 patients) or nearly complete (2 patients) TME quality and negative CRM were achieved in all patients. Our primary endpoint of successful treatment was thus achieved in all cases.

The median number of harvested lymph nodes was 15.5 (642). Median distance of the CRM and distal resection margin from the tumor was $8.0(1.5-17)$ and $27.5 \mathrm{~mm}(5-70 \mathrm{~mm})$, respectively.

Detailed pathologic outcomes including cancer stage are shown in Table 3. 

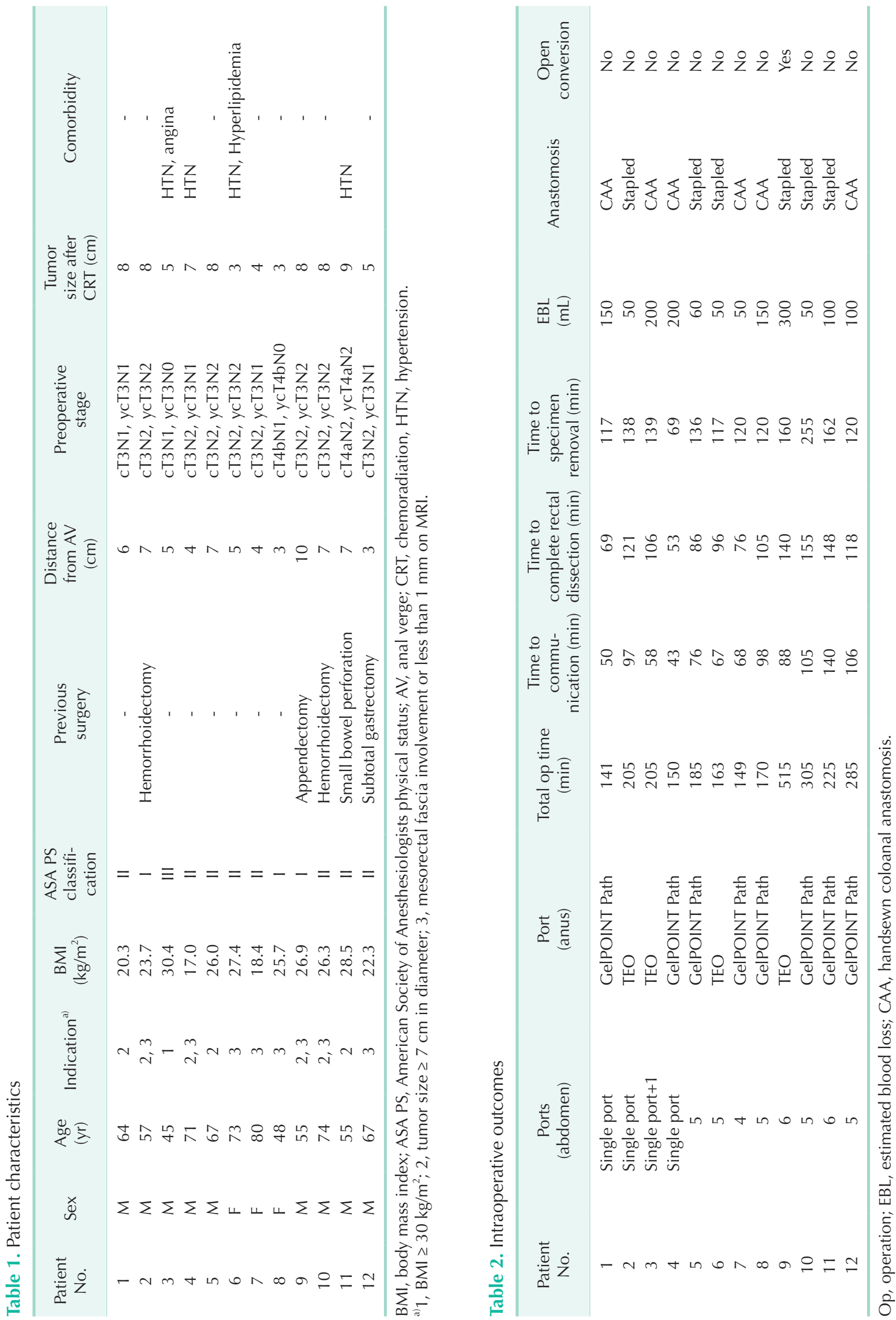
Table 3. Pathologic outcomes

\begin{tabular}{|c|c|c|c|c|c|c|c|c|}
\hline $\begin{array}{l}\text { Patient } \\
\text { No. }\end{array}$ & $\begin{array}{c}\text { TME } \\
\text { quality }\end{array}$ & $\begin{array}{l}\text { TNM } \\
\text { stage }\end{array}$ & PRM (mm) & $\begin{array}{l}\text { DRM } \\
(\mathrm{mm})\end{array}$ & $\begin{array}{l}\text { CRM } \\
(\mathrm{mm})\end{array}$ & $\begin{array}{c}\text { No. of } \\
\text { harvested } \\
\text { LNs }\end{array}$ & $\begin{array}{l}\text { Tumor size } \\
\quad(\mathrm{mm})\end{array}$ & $\begin{array}{l}\text { Specimen } \\
\text { length }(\mathrm{cm})\end{array}$ \\
\hline 1 & Complete & ypT3N0 & 85 & 47 & 9 & 6 & 20 & 15 \\
\hline 2 & Complete & урT3N0 & 87 & 60 & 17 & 21 & 16 & 17.2 \\
\hline 3 & Complete & ypT1N0 & 195 & 10 & 11 & 14 & 27 & 24 \\
\hline 4 & Nearly complete & ypT3N1c & 105 & 5 & 7 & 8 & 41 & 14.5 \\
\hline 5 & Complete & урT3N0 & 150 & 34 & 12 & 25 & 4 & 21.8 \\
\hline 6 & Complete & ypT3N2a & 125 & 21 & 9 & 17 & 28 & 17 \\
\hline 7 & Nearly complete & урT3N1c & 130 & 5 & 2 & 29 & 42 & 17 \\
\hline 8 & Complete & урTONO & $\mathrm{N} / \mathrm{A}$ & $\mathrm{N} / \mathrm{A}$ & $\mathrm{N} / \mathrm{A}$ & 13 & No tumor & 18 \\
\hline 9 & Complete & урT3N1b & 230 & 70 & 5 & 21 & 70 & 33 \\
\hline 10 & Complete & урT3N1a & 360 & 35 & 1.5 & 14 & 55 & 54.8 \\
\hline 11 & Complete & урT0N1 & $\mathrm{N} / \mathrm{A}$ & $\mathrm{N} / \mathrm{A}$ & $\mathrm{N} / \mathrm{A}$ & 42 & No tumor & 19 \\
\hline 12 & Complete & yрT2N0 & 368 & 6 & 4 & 14 & 18 & 38 \\
\hline
\end{tabular}

TME, total mesorectal excision; PRM, proximal resection margin; DRM, distal resection margin; CRM, circumferential resection margin; LN, lymph node; N/A, not applicable.

Table 4. Postoperative outcomes

\begin{tabular}{|c|c|c|c|c|c|c|}
\hline $\begin{array}{l}\text { Patient } \\
\text { No. }\end{array}$ & $\begin{array}{l}\text { Time to } \\
\text { flatus (day) }\end{array}$ & $\begin{array}{l}\text { LOS } \\
\text { (day) }\end{array}$ & $\begin{array}{c}\text { 30-Day postoperative } \\
\text { morbidity }\end{array}$ & $\begin{array}{l}\text { Treatment of } \\
\text { complication }\end{array}$ & $\begin{array}{l}\text { Ileostomy } \\
\text { repair }\end{array}$ & Disease status \\
\hline 1 & 1 & 10 & - & - & Yes & NED \\
\hline 2 & 2 & 11 & Ileus & Conservative & Yes & NED \\
\hline 3 & 1 & 8 & - & - & Yes & NED \\
\hline 4 & 6 & 18 & - & - & Yes & Death \\
\hline 5 & 1 & 7 & - & - & Yes & NED \\
\hline 6 & 1 & 7 & Wound (stoma) & Conservative & Yes & Lung metastasis \\
\hline 7 & 2 & 22 & - & - & Yes & NED \\
\hline 8 & 1 & 9 & - & - & Yes & NED \\
\hline 9 & 4 & 11 & - & - & Yes & Lung metastasis \\
\hline 10 & 1 & 8 & Anastomotic dehiscence & Conservative & Yes & NED \\
\hline 11 & 2 & 7 & - & - & Yes & NED \\
\hline 12 & 1 & 10 & - & - & Yes & NED \\
\hline
\end{tabular}

LOS, length of stay; NED, no evidence of disease.

\section{Postoperative outcome}

The first flatus after surgery was identified at a median of 1 (range, 1-6) day, and the median postoperative hospital stay was 10 days (range, 7-22 days). There was no postoperative 30day mortality, but postoperative 30-day morbidities occurred in 3 patients including a case of postoperative ileus, which spontaneously resolved by conservative management; a case of wound problem near the stoma site; and a case of anastomotic dehiscence. The patient with anastomotic dehiscence complained of perianal pain and fluid collection around the anastomotic site was observed on pelvic CT. The patient's symptoms disappeared after anti-inflammatory drug treatment they underwent ileostomy repair surgery as planned after chemotherapy. All complications were classified as ClavienDindo grade II.

\section{Postoperative follow-up}

The remaining 11 patients received chemotherapy after radical surgery, except for 1 patient who underwent psychiatric treatment for depression and anxiety. The anticancer regimens used included 6 cycles of capecitabine in 6 patients, 2 cycles of 5 -fluorouracil and leucovorin (FL) in 1, and 8 cycles of FL plus oxaliplatin in 4. In all patients, ileostomy repair operations were performed at a median of 182 days (range, 98-201 days) after transanal TME. The median follow-up period after surgery was 13 months (8-31 months). Lung metastases appeared in 2 at 6 and 10 months postoperatively, respectively. The patient that had undergone psychiatric treatment died 9 months after surgery for reasons unrelated to the disease. The other 9 patients are being followed up without recurrence of the disease (Table 4). 


\section{DISCUSSION}

The present prospective study was designed to assess the technical feasibility, including the adequacy of oncologic resection and perioperative outcomes, of TME in difficult laparoscopic cases including those in obese patients or patients with bulky tumors or tumors threatening the mesorectal fascia. This study found that complete or nearly complete TME was achieved in all 12 patients with acceptable perioperative outcomes.

Laparoscopic surgery has been widely used for colon cancer surgery since 2004 as it achieves earlier recovery and satisfactory oncologic outcomes [2]. However, laparoscopic surgery for low rectal cancer has so far been limited to the experienced surgeon because of the limited movement of the straightened laparoscopic instruments in the narrow pelvic cavity [3,4]. Thus, the conversion rate during laparoscopic TME surgery has been reported to be as high as $5 \%-30 \%[6,7]$. Recently, robotic surgery and transanal approaches have been proposed as solutions to this problem. In robotic surgery, a surgical tool with a joint can help during the lower rectal dissection, whereas transanal TME can achieve a good visual field with a direct approach to the lower pelvis through the anus [18-20].

In 2008, Funahashi et al. [8] proposed a down-to-up rather than an up-to-down approach in rectal cancer patients with a narrow pelvic cavity or a large bulky tumor. They did not use a laparoscopic instrument through the anus and would not have been able to reach the peritoneal reflexion, although the dissection of the lower rectum would be possible using conventional surgical tools. Since then, several studies have attempted transanal TME surgery in cases where laparoscopic access is challenging, but no prospective studies with strict inclusion criteria have been conducted $[9,10]$. Access from below through the anus provides a new surgical field of view that conventional laparoscopic surgery has not previously achieved. It provides a clear view of the surgical field enabling safe dissection of the rectum from the surrounding tissue. As a result, it can be expected to aid in safely and completely removing the tumor while preserving the nerve tissue around the rectum. However, the merits of the transanal approach have not been verified. In fact, even the definitions of transanal TME are still controversial. According to the results reported in the international transanal TME registry [21], anterior dissection is usually performed to Denonvilliers' fascia, with posterior dissection normally performed to $8-10 \mathrm{~cm}$ from the anal verge. In the ongoing COLOR III trial [22], transanal TME is defined as minimal dissection of the distal one-third of the mesorectum with the extent of transanal dissection decided by the surgical team according to individual case parameters. As we described in the operative techniques section, we usually performed transanal dissection anteriorly to the peritoneal reflection and posteriorly to the promontory. However, in the simultaneous 2-team approach, the level of transabdominal and transanal dissection can vary among cases. Usually, we perform transanal dissection as far as possible via the level of the tumor until the planes of dissection communicate with each other.

The main outcome measures in our study were TME quality and CRM positivity. This enables us to evaluate not only the quality of the surgical technique but also oncological outcomes influencing the prognosis of rectal cancer. However, to demonstrate the advantages of the transanal approach in obese patients with a narrow pelvis or bulky tumors, it is necessary to show that surgeons can successfully overcome the technical difficulties through reducing operation time or conversion rate. The median total operation time in our study was 191 minutes, and the conversion rate was $8.3 \%$ ( 1 of 12 cases). In the case needing conversion, bulky tumors invading the ureter were removed en bloc, followed by ureterocystostomy using an open approach. Although we cannot directly compare our results with other published studies, the operation time and conversion rates in our study were not significantly different to previous reports $[4,5,18,21]$. This may be an indirect indication of the advantages of our approach since our study cohort comprised challenging cases only.

The present study is limited by the small number of patients with strict inclusion criteria. Due to the strict indications adopted, it took a relatively long time to enroll the patients despite the small number. In addition, only 1 obese patient with a BMI of over $30 \mathrm{~kg} / \mathrm{m}^{2}$ was enrolled because rectal cancer patients with severe obesity are still rare in Eastern countries. The low rate of high BMI, especially in Korea, may be a reason for the low conversion rate to laparoscopic surgery for rectal cancer [3]. However, the number of obese patients continues to increase and the high conversion rate in obese patients is not an exception in Korea. In our experience, the conversion rate in patients with high BMI was about $15 \%$, which was not significantly different from that reported in Western countries [23]. Thus, new approaches using transanal TME or robotic TME, which are expected to make the procedure more feasible in obese patients, will also become more important in Eastern countries.

Furthermore, since all patients underwent ileostomy and were not followed-up for an acceptable period afterward, this report did not address the functional outcome after surgery. The functional outcome of patients undergoing transanal TME surgery will be reported in the near future along with the longterm oncologic outcome after additional follow-up. Finally, the surgeons who participated in this study were already very experienced with both laparoscopic and transanal TME for rectal cancer. Because standardized transanal TME procedures and formal training programs are not yet established, surgeons 
should gain sufficient experience with simple cases before progressing to more difficult ones [24,25]. Transanal TME requires new equipment, such as a transanal platform and continuous air insufflation system. Furthermore, the procedure is burdened by the need for 2 experienced surgeons and 2 laparoscopy systems for transabdominal and transanal access. Transanal TME also has a steep learning curve and a surgeon must encounter many cases before becoming proficient. Because of these limitations, transanal TME has not spread rapidly in Korea, and robot-assisted surgery is now playing a role as an alternative to lower rectal cancer surgery. Despite these limitations, in our initial experiences of transanal TME, we identified some advantages of the transanal approach in difficult laparoscopic cases, such as better surgical view, simple handling of laparoscopic instruments, and avoidance of the limitation of movements caused by pelvic bone. These advantages help surgeons to remove all tumors even in cases with a threatened mesorectal fascia and to find the proper dissection plane without any visual barriers in patients with obesity or bulky tumors. Thus, with technological advances, robotic TME and transanal TME can be considered as alternative options for overcoming the limitations of conventional laparoscopic TME, especially in challenging cases.

In conclusion, this study has demonstrated the feasibility of transanal TME in difficult laparoscopic cases including obese patients or patients with bulky tumors or tumors threatening the mesorectal fascia. Additional studies involving more patients will be needed in the near future.

\section{CONFLICTS OF INTEREST}

No potential conflict of interest relevant to this article was reported.

\section{ACKNOWLEDGEMENTS}

This work was supported by a National Cancer Center Grant (NCC-1510150 and NCC-1810190).

\section{REFERENCES}

1. Martling AL, Holm T, Rutqvist LE, Moran BJ, Heald RJ, Cedemark B. Effect of a surgical training programme on outcome of rectal cancer in the County of Stockholm. Stockholm Colorectal Cancer Study Group, Basingstoke Bowel Cancer Research Project. Lancet 2000;356:93-6.

2. Clinical Outcomes of Surgical Therapy Study Group, Nelson H, Sargent DJ, Wieand HS, Fleshman J, Anvari M, et al. A comparison of laparoscopically assisted and open colectomy for colon cancer. $\mathrm{N}$ Engl J Med 2004:350:2050-9.

3. Jeong SY, Park JW, Nam BH, Kim S, Kang SB, Lim SB, et al. Open versus laparoscopic surgery for mid-rectal or low-rectal cancer after neoadjuvant chemoradiotherapy (COREAN trial): survival outcomes of an open-label, non-inferiority, randomised controlled trial. Lancet Oncol 2014;15:76774.

4. Kang SB, Park JW, Jeong SY, Nam BH, Choi HS, Kim DW, et al. Open versus laparoscopic surgery for mid or low rectal cancer after neoadjuvant chemoradiotherapy (COREAN trial): short-term outcomes of an open-label randomised controlled trial. Lancet Oncol 2010;11:637-45.

5. van der Pas MH, Haglind E, Cuesta MA, Furst A, Lacy AM, Hop WC, et al. Laparoscopic versus open surgery for rectal cancer (COLOR II): short-term outcomes of a randomised, phase 3 trial. Lancet Oncol 2013;14:210-8.

6. Thorpe H, Jayne DG, Guillou PJ, Quirke P, Copeland J, Brown JM, et al. Patient factors influencing conversion from laparoscopically assisted to open surgery for colorectal cancer. Br J Surg 2008;95:199205.

7. Allaix ME, Furnee EJ, Mistrangelo M, Arezzo A, Morino M. Conversion of laparoscopic colorectal resection for cancer: what is the impact on short-term outcomes and survival? World J Gastroenterol 2016;22:8304-13.

8. Funahashi K, Koike J, Teramoto T, Saito $\mathrm{N}$, Shiokawa H, Kurihara A, et al. Transanal rectal dissection: a procedure to assist achievement of laparoscopic total mesorectal excision for bulky tumor in the narrow pelvis. Am J Surg 2009;197: e46-50.

9. Rouanet P, Mourregot A, Azar CC, Carrere S, Gutowski M, Quenet F, et al. Transanal endoscopic proctectomy: an innovative procedure for difficult resection of rectal tumors in men with narrow pelvis. Dis Colon Rectum 2013:56:408-15.

10. Dumont F, Goere D, Honore C, Elias D. Transanal endoscopic total mesorectal excision combined with single-port laparoscopy. Dis Colon Rectum 2012;55:9961001.

11. Sylla P, Rattner DW, Delgado S, Lacy AM. NOTES transanal rectal cancer resection using transanal endoscopic microsurgery and laparoscopic assistance. Surg Endosc 2010;24:1205-10.

12. Emhoff IA, Lee GC, Sylla P. Transanal colorectal resection using natural orifice translumenal endoscopic surgery (NOTES). Dig Endosc 2014;26 Suppl 1:2942.

13. Sohn DK, Jeong SY, Park JW, Kim JS, Hwang JH, Kim DW, et al. Comparative study of NOTES rectosigmoidectomy in a swine model: E-NOTES vs. P-NOTES. 
Endoscopy 2011;43:526-32.

14. Kim T, Sohn DK, Park JW, Park CH, Moon $\mathrm{SH}$, Chang HJ, et al. Transanal rectosigmoidectomy using a single port in a Swine model. Surg Innov 2013;20:225-9.

15. Oh JH, Park SC, Kim MJ, Park BK, Hyun JH, Chang HJ, et al. Feasibility of transanal endoscopic total mesorectal excision for rectal cancer: results of a pilot study. Ann Surg Treat Res 2016;91:187-94.

16. Quirke P, Durdey P, Dixon MF, Williams NS. Local recurrence of rectal adenocarcinoma due to inadequate surgical resection. Histopathological study of lateral tumour spread and surgical excision. Lancet 1986:2:996-9.

17. Clavien PA, Barkun J, de Oliveira ML, Vauthey JN, Dindo D, Schulick RD, et al. The Clavien-Dindo classification of surgical complications: five-year experience. Ann Surg 2009:250:187-96.

18. Jayne D, Pigazzi A, Marshall H, Croft J, Corrigan N, Copeland J, et al. Effect of robotic-assisted vs conventional laparoscopic surgery on risk of conversion to open laparotomy among patients undergoing resection for rectal cancer: the ROLARR randomized clinical trial. JAMA 2017:318:1569-80.

19. de Lacy AM, Rattner DW, Adelsdorfer C, Tasende MM, Fernandez M, Delgado S, et al. Transanal natural orifice transluminal endoscopic surgery (NOTES) rectal resection: "down-to-up" total mesorectal excision (TME)--short-term outcomes in the first 20 cases. Surg Endosc 2013;27:316572.

20. Wolthuis AM, de Buck van Overstraeten A, D'Hoore A. Dynamic article: transanal rectal excision: a pilot study. Dis Colon Rectum 2014:57:105-9.

21. Penna M, Hompes R, Arnold S, Wynn G, Austin R, Warusavitarne J, et al. Transanal total mesorectal excision: international registry results of the first 720 cases. Ann Surg 2017;266:111-7.
22. Deijen CL, Velthuis S, Tsai A, Mavroveli S, de Lange-de Klerk ES, Sietses C, et al. COLOR III: a multicentre randomised clinical trial comparing transanal TME versus laparoscopic TME for mid and low rectal cancer. Surg Endosc 2016;30:3210-5.

23. Park JW, Lim SW, Choi HS, Jeong SY, Oh JH, Lim SB. The impact of obesity on outcomes of laparoscopic surgery for colorectal cancer in Asians. Surg Endosc 2010; 24:1679-85.

24. McLemore EC, Harnsberger CR, Broderick RC, Leland H, Sylla P, Coker AM, et al. Transanal total mesorectal excision (taTME) for rectal cancer: a training pathway. Surg Endosc 2016;30:4130-5.

25. Francis N, Penna M, Mackenzie H, Carter F, Hompes R; International TaTME Educational Collaborative Group. Consensus on structured training curriculum for transanal total mesorectal excision (TaTME). Surg Endosc 2017;31:2711-9. 